\title{
Mercury in Canned Tuna in Spain. Is Light Tuna Really Light?*
}

\author{
Montserrat González-Estecha ${ }^{1 \#}$, María José Martínez-García², Manuel Fuentes-Ferrer ${ }^{3,4}$, \\ Andrés Bodas-Pinedo ${ }^{5}$, Alfonso Calle-Pascual ${ }^{6}$, José María Ordóñez-Iriarte ${ }^{7}$, \\ Cristina Fernández-Pérez ${ }^{3,4}$, Nieves Martell-Claros ${ }^{8}$, Miguel Ángel Rubio-Herrera ${ }^{6}$, \\ Emilia Gómez-Hoyos ${ }^{6}$, José Jesús Guillén-Pérez ${ }^{9,10}$
}

\begin{abstract}
${ }^{1}$ Trace Element Unit and Laboratory Medicine Department, Instituto de Investigación Sanitaria, Hospital Clínico San Carlos, Madrid, Spain; ${ }^{2}$ Universidad Politécnica, Cartagena, Spain; ${ }^{3}$ Universidad Camilo Jose Cela, Madrid, Spain; ${ }^{4}$ Department of Epidemiology, Instituto de Investigación Sanitaria, Hospital Clínico San Carlos, Madrid, Spain; ${ }^{5}$ Department of Pediatrics, Instituto de Investigación Sanitaria, Hospital Clínico San Carlos, Madrid, Spain; ${ }^{6}$ Department of Endocrinology, Instituto de Investigación Sanitaria, Hospital Clínico San Carlos, Madrid, Spain; ${ }^{7}$ Consejería de Sanidad y Consumo, Madrid, Spain; ${ }^{8}$ Hypertension Unit, Instituto de Investigación Sanitaria, Hospital Clínico San Carlos, Madrid, Spain; ${ }^{9}$ Publich Health Department, Cartagena, Spain; ${ }^{10}$ Universidad de Murcia, Murcia, Spain.

Email: ${ }^{*}$ montse@cmpx.net
\end{abstract}

Received May $6^{\text {th }}, 2013$; revised June $6^{\text {th }}, 2013$; accepted June $14^{\text {th }}, 2013$

Copyright (C) 2013 Montserrat González-Estecha et al. This is an open access article distributed under the Creative Commons Attribution License, which permits unrestricted use, distribution, and reproduction in any medium, provided the original work is properly cited.

\begin{abstract}
In Spain, certain population-based studies have shown high blood mercury ( $\mathrm{Hg}$ ) levels due to the high consumption of fish. Some studies have stated that one of the most consumed fish in Spain is canned tuna. Different Spanish organisms consider that it is safe to consume canned tuna as it supposedly has a low mercury content, particularly in so-called light tuna. However, in Spain light tuna is mainly yellowfin and bigeye tuna, while in other countries it is mainly skipjack tuna. This study analyzed 36 cans of the most popular brands in Spain and examined the influence of the type of tuna, packaging medium (olive oil, sunflower seed oil, water or marinade), different brands, prices and expiration dates. Mercury concentrations ( $\mathrm{mg} / \mathrm{kg}$ ) were measured by atomic absorption spectrometry and thermal decomposition amalgamation. The medians observed were $(\mathrm{mg} / \mathrm{kg})$ : light tuna: 0.314; IQR: 0.205 - 0.594, white tuna: 0.338 ; IQR: 0.276 0.558, skipjack: 0.311; IQR: 0.299 - 0.322, frigate tuna: 0.219 ; IQR $0.182-0.257$ and mackerel: 0.042 ; IQR $0.029-$ 0.074 . We found statistically significant differences between white tuna, light tuna and mackerel $(p=0.004)$; light tuna and mackerel $(p=0.002)$ and white tuna and mackerel $(p=0.006)$. However, we found no differences between white tuna and light tuna, or among packaging medium, brands, prices or expiration dates. The limit of $0.500 \mathrm{mg} / \mathrm{kg}$ of mercury in canned tuna was exceeded by the following percentages of the cans: $33.3 \%$ of light tuna, $16.7 \%$ of white tuna, and $0 \%$ of Skipjack, frigate tuna and mackerel. The mercury content of the cans of Spanish light tuna that were analyzed was variable and high. The results of this study indicate that stricter regulation of $\mathrm{Hg}$ in canned tuna is necessary. Until then, it is safer to recommend that vulnerable populations such as children and pregnant women consume canned mackerel, which has a markedly lower mercury content.
\end{abstract}

Keywords: Mercury; Canned Tuna; Spain

\section{Introduction}

Methylmercury (MeHg) is a widespread and particularly toxic form of $\mathrm{Hg}$ that results from the conversion of inorganic $\mathrm{Hg}$ to a methylated form by aquatic microorgan-

*The authors of this paper do not have any commercial associations that might pose a conflict of interest in connection with this manuscript.

${ }^{\#}$ Corresponding author. isms and can bioaccumulate in the aquatic food web. Methylmercury accounts for more than $90 \%$ of total mercury content in fish and is attached to the thiol group of the cysteine residues in fish protein, and is thus not eliminated by cleaning or cooking the fish. Nevertheless, although fish may contain harmful compounds, it is also a very important source of nutrients, especially longchain n-3 fatty acids, high quality protein, selenium and 
vitamin $\mathrm{D}$, and is relatively low in cholesterol [1].

Dietary intake of MeHg through ingestion of contaminated fish is a public health concern, primarily due to its neurodevelopmental toxicity in fetuses and children. Transplacental exposure is particularly dangerous, as the fetal brain is very sensitive. Neurological symptoms include mental retardation, seizures, vision and hearing loss, delayed development, language disorders and memory loss. In addition, a growing body of evidence suggests that $\mathrm{MeHg}$ exposure may also lead to an increased risk of adverse cardiovascular impact in exposed adult populations $[2,3]$.

At the international level, the JECFA (Joint FAO/ WHO Expert Comittee on Food Additives) expresses risk as the provisional tolerable weekly intake (PTWI), which has been $1.6 \mu \mathrm{g} \mathrm{MeHg} / \mathrm{kg}$ body weight since 2003. At the end of 2012, the European Food Safety Authority (EFSA) updated advice on risks for public health. At the request of the European Commission, EFSA's Scientific Panel on Contaminants in the Food Chain (CONTAM Panel) has reported that, for $\mathrm{MeHg}$, new studies indicate that beneficial effects related to long chain omega 3 fatty acids present in fish may have previously led to an underestimation of the potential adverse effects of $\mathrm{MeHg}$ in fish. The Panel has therefore proposed a TWI for MeHg of $1.3 \mu \mathrm{g} / \mathrm{kg} / \mathrm{bw}$, which is lower than JECFA's $1.6 \mu \mathrm{g} /$ $\mathrm{kg} / \mathrm{bw}$ [4]. However, this newly proposed TWI is still higher than the TWI in the United States (US). The US Environmental Protection Agency (EPA) and the National Academy of Sciences established a reference dose of $0.7 \mu \mathrm{g} \mathrm{MeHg} / \mathrm{kg} / \mathrm{bw}$ in 2000 , which led to the US EPA's value of $0.5 \mathrm{mg} / \mathrm{kg}$ as an acceptable standard of $\mathrm{Hg}$ in fish for human consumption (this corresponds to the $\mathrm{MeHg}$ limit of $5.8 \mu \mathrm{g} / \mathrm{L}$ in blood) [5]. However, the US Food and Drug Administration (FDA)'s action level for $\mathrm{Hg}$ in tuna is $1 \mathrm{mg} / \mathrm{kg}$ [6].

The European Union (EU) has established a Hg limit of $0.5 \mathrm{mg} / \mathrm{kg}$ for fresh fish, except for certain fish such as tuna, which has a limit of $1 \mathrm{mg} / \mathrm{kg}$ [7].

Spain is one of the countries of the EU with a highest consumption of seafood and, according to different population-based studies carried out in recent years, it is also one of the countries with the highest blood mercury concentrations [8]. However, fish consumption in Spain has decreased in recent years, down to a consumption of $26.37 \mathrm{~kg}$ per capita in 2012. In spite of this overall decrease, consumption of tuna fish increased $14.6 \%$ from 2011 to 2012. Taking into account only canned tuna, it is the second most consumed seafood product (behind hake) in Spain, with a consumption of $2.25 \mathrm{~kg}$ per capita in 2012, representing $8.5 \%$ of total fish consumption [9].

In the US, canned tuna is also the second most frequently consumed seafood product, at $1.2 \mathrm{~kg}$ per person per year in 2011. Light tuna, which consists mostly of skip- jack (Katsuwonus pelamis) and small amounts of yellowfin (Thunnus albacares) is the least expensive product and represents the largest portion of canned tuna sales in the US. Albacore tuna (Thunnus alalunga) is the only species authorized to be labeled "White tuna" in the US [10].

The average size is different among the types of tuna. White tuna (Thunnus alalunga) has a maximum weight of around $40 \mathrm{~kg}$ at 15 years, while the maximum for Skipjack (Katsuwonus pelamis) is about $30 \mathrm{~kg}$ at 15 years. The maximum weight of Yellowfin (Thunnus albacares) is about $175 \mathrm{~kg}$ at 8 years and bigeye (Thunnus obesus) has a maximum of about $210 \mathrm{~kg}$ at 15 years. Bigeye tuna are similar to Yellowfin tuna, and in fact they are sometimes hard to distinguish [11]. These designations are standardized by the FDA with reference to a Munsell gradient of darkness. White tuna is not darker than Munsell value of 6.3 and light tuna ranges from Munsell 6.3 to not darker than 5.3 [12].

With respect to canned tuna, in 2004 the US EPA and FDA recommended that vulnerable groups such as pregnant women and small children eat up to 12 ounces (2 average meals) a week of canned light tuna and stated that albacore ("white") tuna has more mercury than canned light tuna. So, when choosing the two meals of fish and shellfish, it is recommended to eat only up to 6 ounces (one average meal) of albacore tuna per week [13].

In Spain, in April 2011 the Spanish Agency for Food Safety and Nutrition (AESAN) published its recommendations on seafood consumption by pregnant women and small children, which made no mention of canned tuna. However, the FAQ section of its webpage states the following: species that are used for canned tuna are much smaller, thus their mercury content is considerably reduced [14].

Light tuna is recommended in other countries because of its lower mercury content, but in Spain it is made up of different species of tuna. Thus, cans of skipjack ( $\mathrm{Ka}-$ tsuwonus pelamis) in Spain are simply called canned tuna or striped tuna. In addition, new legislation approved in August 2009 stated that the previous Royal Decree of 1984 had provided the name light tuna only for Thunnus albacares (yellowfin). However, the Spanish market has admitted that since 2002 other species of tuna have been labeled as light tuna, particularly bigeye tuna (Thunnus obesus). Thus, this new legislation declared it convenient to allow bigeye tuna to be labeled as both tuna and light tuna [15]. Therefore, given the different species of tuna labeled as light tuna in Spain, and taking into account the high consumption of canned tuna by the Spanish population as well as the high blood mercury concentrations found by different studies, it would be desirable to know the concentration of mercury in the varieties of canned tuna most frequently consumed in Spain before making recommendations to vulnerable populations. 
The objective of this study is to measure mercury concentrations in the most popular brands of canned tuna in Spain and to examine the influence of type of tuna, packaging medium, store brand, price and expiration date.

\section{Material And Methods}

\subsection{Canned Tuna Samples}

The present descriptive study used a non-probability sampling method which included 36 cans of the most popular brands of tuna in Spain purchased from 4 different grocery stores in Madrid and 4 in Cartagena (Spain) during September 2012.

We examined the type of tuna: light tuna, white (albacore) tuna (Thunnus alalunga), skipjack (Katsuwonus pelamis), frigate tuna (Auxis thazard) and Pacific (chub) mackerel (Scomber japonicus). In addition, in the group of light tuna, information regarding the type of tuna was also collected: yellowfin (Thunnus albacares), bigeye (Thunnus obesus) or unspecified. We analyzed other variables such as packaging medium (olive oil, sunflower seed oil, water and marinade), brand of tuna (store brand or not), price and expiration date.

\subsection{Mercury Analyses}

Total mercury concentrations $(\mathrm{Hg})$ were measured using a direct mercury method based on the EPA 7473 analytical procedure: thermal decomposition, catalytic reduction, amalgamation, desorption and atomic absorption spectrometry. The analyses were performed in the Trace Element Laboratory of the hospital Clínico San Carlos of Madrid in a Perkin Elmer SMS-100 analyzer and in the Laboratory of the Chemical and Environmental Engineering Department of the Universidad Politécnica de Cartagena in a Milestone DMA-80 spectrophotometer. We carried out comparisons of samples between the two laboratories and the concordance was excellent, with an intraclass correlation close to 1 . Two calibration graphs of 0 - $50 \mathrm{ng}$ and 50 - $500 \mathrm{ng}$ of mercury were generated from aqueous standards in $10 \%$ nitric acid. A detection limit of $0.005 \mathrm{ng}$ of mercury was achievable while a maximum concentration of $20 \mu \mathrm{g}$ of mercury was allowed.

All the analyses were done on individual cans. The contents were drained and a small amount of fresh tissue of approximately $0.1 \mathrm{~g}$ was weighed into a nickel sample boat, avoiding contamination in both the collection and handling of samples. Duplicated samples were measured from all cans with a mean reproducibility of $4.5 \%$ (range 0.1 - 13.5), and the samples with high results $(>0.500$ $\mathrm{mg} / \mathrm{kg}$ ) were analyzed again.

All analyzed samples were within the calibration range. Total mercury concentration was reported as $\mathrm{mg} / \mathrm{kg}$ on a wet weight basis, rounded to three significant decimal points.

Internal quality controls (Seronorm ${ }^{\circledR}$ trace element levels 1 and 2) were assessed in every series of samples to check the reproducibility and accuracy of the measurements. In addition, the Madrid laboratory took part in two external quality assessment schemes with excellent performance: the European Occupational and Environmental Laboratory Medicine (OELM) program and the one organized by the University of Surrey, Guildford (Surrey, UK).

\subsection{Statistical Analyses}

Qualitative variables were summarized as a frequency distribution and continuous non-normally distributed variables were summarized as median and interquartile range (IQR).

The non parametric Kruskall-Wallis test was used to compare quantitative variables between more then to two independent groups, or the Mann-Whitney test for to two independent groups. Spearman correlation coefficient was used to analyse the correlation between continuous variables.

The null hypothesis was rejected by a type I error $<0.05(\alpha<0.05)$. Statistical analyses were performed using SPSS 15.0 (SPSS Inc., Chicago, Illinois, USA), and figure using GraphPad Prism 5.00 (GraphPad Software, San Diego, California, USA).

\section{Results}

Table 1 summarizes the different mercury concentrations in each of the types of tuna. An overall median mercury concentration of $0.298 \mathrm{mg} / \mathrm{kg}$ (IQR: 0.191 - 0.470) was obtained. The limit of $0.500 \mathrm{mg} / \mathrm{kg}$ of mercury was exceeded by $22.2 \%$ of the total of canned tuna.

Figure 1 shows the distribution of mercury concentrations according to the type of tuna. We found statistically significant differences between white tuna, light tuna and mackerel $(p=0.004)$; light tuna and mackerel $(p=0.002)$ and white tuna and mackerel $(p=0.006)$. However, we found no differences between white tuna and light tuna $(p=0.755)$.

With respect to the packaging medium in the canned tuna, no statistically significant differences $(p=0.105)$ were observed in mercury medians in the tuna among olive oil ( $n=21$; median: 0.298 ; IQR: $0.176-0.564$ $\mathrm{mg} / \mathrm{kg})$, sunflower seed oil $(n=6$; median: 0.194; IQR: $0.063-0.269 \mathrm{mg} / \mathrm{kg}$ ), and the water packaging medium ( $n=8$; median: 0.377; IQR: $0.230-0.588 \mathrm{mg} / \mathrm{kg}$ ). Nor were statistically significant differences $(p=0.733)$ found in mercury concentrations in relation to store brand: median 0.296; IQR: $0.201-0.562$ vs. the median 0.299 ; IQR: $0.08-0.404 \mathrm{mg} / \mathrm{kg}$ of non store brand tuna.

Regarding the price, the overall median price per gram 
Table 1. Mercury in canned tuna.

\begin{tabular}{|c|c|c|c|c|c|c|c|}
\hline Type of tuna & $\mathrm{N}$ & Median $^{*}$ & $\mathrm{IQR}^{*}$ & $\operatorname{Min}^{*}$ & $\operatorname{Max}^{*}$ & $p$ & $n(\%)$ over $0.5 \mathrm{mg} / \mathrm{kg}$ \\
\hline Light tuna & 21 & 0.314 & $0.205-0.594$ & 0.031 & 1.176 & \multirow{6}{*}{0.004} & $7(33.3)$ \\
\hline White tuna & 6 & 0.338 & $0.276-0.558$ & 0.225 & 0.965 & & $1(16.7)$ \\
\hline Mackerel & 5 & 0.042 & $0.029-0.075$ & 0.023 & 0.076 & & $0(0.0)$ \\
\hline Skipjack & 2 & 0.311 & $0.299-0.322$ & 0.299 & 0.322 & & $0(0.0)$ \\
\hline Frigate tuna & 2 & 0.220 & $0.182-0.257$ & 0.182 & 0.257 & & $0(0.0)$ \\
\hline Total & 36 & 0.298 & $0.191-0.470$ & 0.023 & 1.176 & & $8(22.2)$ \\
\hline \multicolumn{8}{|c|}{ Light tuna $(n=21)$} \\
\hline \multicolumn{8}{|l|}{ Packaging medium } \\
\hline Olive oil & 9 & 0.561 & $0.196-0.963$ & 0.031 & 1.176 & \multirow{4}{*}{0.233} & $5(55.6)$ \\
\hline Sunflower seed oil & 3 & 0.201 & $0.187-0.251$ & 0.187 & 0.251 & & $0(0.0)$ \\
\hline Water & 8 & 0.377 & $0.230-0.588$ & 0.201 & 0.822 & & $2(25.0)$ \\
\hline Marinade & 1 & 0.314 & $0.314-0.314$ & 0.314 & 0.314 & & $0(0.0)$ \\
\hline \multicolumn{8}{|l|}{ Type of light tuna } \\
\hline Yellowfin & 4 & 0.282 & $0.203-0.388$ & 0.201 & 0.398 & \multirow{2}{*}{0.446} & $0(0.0)$ \\
\hline Unspecified & 17 & 0.314 & $0.212-0.722$ & 0.031 & 1.176 & & $7(41.2)$ \\
\hline \multicolumn{8}{|l|}{ Store brand } \\
\hline Yes & 15 & 0.314 & $0.208-0.566$ & 0.187 & 0.949 & \multirow{2}{*}{0.969} & $5(33.3)$ \\
\hline No & 6 & 0.348 & $0.135-1.027$ & 0.031 & 1.176 & & $2(33.3)$ \\
\hline \multicolumn{8}{|c|}{ Lineal correlation between price, expiration date and mercury concentration } \\
\hline & $r$ & $p$ & & & & & \\
\hline Price (euro cents) & 0.152 & 0.377 & $1.278(\text { IQR: } 1.003-2.337)^{\mathrm{a}}$ & & & & \\
\hline Expiration date (months) & 0.155 & 0.368 & $62.17(13.49)^{\mathrm{b}}$ & & & & \\
\hline
\end{tabular}

${ }^{*}$ Concentrations are in $\mathrm{mg} / \mathrm{kg}$ on wet weight basis; ${ }^{\mathrm{a}}$ Median and interquartile range; ${ }^{\mathrm{b}}$ Mean and standard deviation.

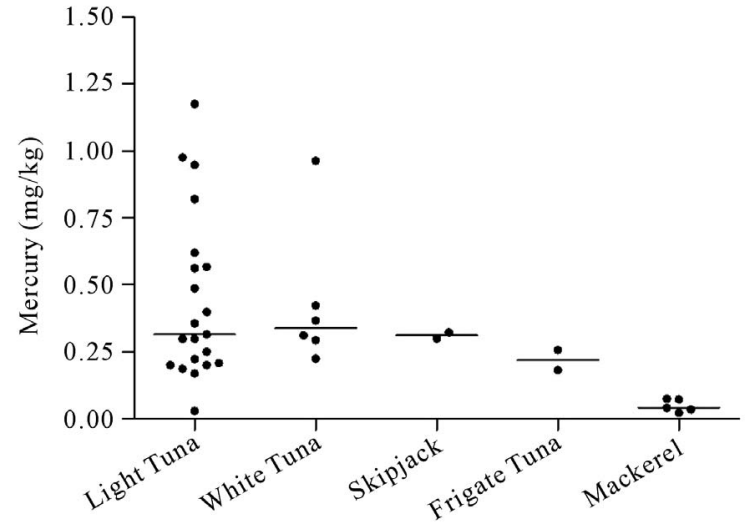

Figure 1. Scatter plot mercury concentration in canned tuna. The horizontal line represents the median value.

of tuna expressed in euro cents was 1.278; IQR $=1.003$ 2.337. We found no correlation between mercury concentration and price $(r=0.152 ; p=0.377)$ or between mercury concentration and expiration date (mean: 62.17; SD: 13.49 months) of the cans $(r=0.155 ; p=0.368)$.

In addition, Table 1 shows the results of mercury concentrations in light tuna. One can of light tuna was over $(1.176 \mathrm{mg} / \mathrm{kg})$ the limit set in Spain $(1 \mathrm{mg} / \mathrm{kg})$, exceeding the limit of $0.500 \mathrm{mg} / \mathrm{kg}$ of mercury by $33.3 \%$. We also did not observe statistically significant differences $(p=$ 0.233 ) in mercury medians among olive oil, sunflower seed oil and the water packaging medium. In the comparison of mercury concentrations regarding the type of light tuna, none of the cans described its contents as bigeye type and no statistically significant difference ( $p=$ 0.446 ) was found between yellowfin and unspecified tuna, or by store brand $(p=0.969)$.

\section{Discussion}

Until recently, relatively little attention has been devoted to examining mercury in canned tuna, despite its great importance in human diets. There is substantial media coverage of the benefits and risk from fish consumption, but few peer-reviewed data on canned tuna, the second most commonly consumed seafood in the US as well as in Spain [9,10].

It is often assumed, even in fish advisories such as that of the Spanish Agency for Food Safety and Nutrition, that fresh tuna have higher mercury levels than canned tuna, but the literature does not provide clear evidence for this. In fact, although the average size of tuna may 
have declined, the mercury levels in canned tuna have not and may have increased [12].

Among the different types of canned tuna, light tuna is generally thought to contain the lowest concentrations of mercury.

However, the most notable finding of our study was that the mercury concentrations of light tuna were actually much higher than those reported by other authors, with levels ranging from 0.031 to $1.176 \mathrm{mg} / \mathrm{kg}$. The median we obtained of $0.314 \mathrm{mg} / \mathrm{kg}$ is much higher than the median reported in 2010 by the F.D.A. of $0.078 \mathrm{mg} / \mathrm{kg}$ (with a mean of $0.128 \mathrm{mg} / \mathrm{kg}$ ) [16]. The main difficulty in comparing results lies in the fact that many studies do not distinguish between different types of tuna; rather, they report global findings. The few published studies that distinguished light tuna from other types have reported mercury concentrations much lower than those found in our study. For example, in 2004 Shim et al. reported a mean of $0.183 \mathrm{mg} / \mathrm{kg}$ in light tuna in vegetable oil and a mean of $0.054 \mathrm{mg} / \mathrm{kg}$ in light tuna in water [17]. Similar results were found by other authors, with a mean in light tuna of $0.137 \mathrm{mg} / \mathrm{kg}$ [18] and $0.118 \mathrm{mg} / \mathrm{kg}$ [12]. A study recently performed by Groth also found a mean of $0.118 \mathrm{mg} / \mathrm{kg}$ in 48 samples of light tuna in the US. Groth's results highlight the differences among country of origin: the lowest levels were found in tuna caught in the US, with light tuna from Ecuador having the highest average level; light tuna from Thailand and the Philippines had intermediate levels [19]. Other authors have also found variation among oceans and countries, probably related to the source of the fishery, species and fish size. Therefore, the location where the tuna was caught is very important [12]. However, the locations used by companies are not available to the consumer, making spatial comparisons difficult.

In accordance with these authors, we believe that it is important to distinguish which types of tuna are safest to consume and to make this information known to the populations most at risk.

Most light tuna analyzed in other literature was made up of skipjack, which in Spain is labeled as striped tuna or simply tuna and is not commonly available. In Spain, light tuna is composed of yellowfin and bigeye. Our results are similar to those of a study performed on yellowfin in Mexico, which found a median of $0.362 \mathrm{mg} / \mathrm{kg}$ in water-packed tuna and $0.258 \mathrm{mg} / \mathrm{kg}$ in oil-packed tuna [20]. According to some authors, yellowfin tuna has medium to high contaminant levels and bigeye has the highest contaminant levels, while atlantic mackerel and skipjack have the lowest contaminant levels [21]. In addition, and as mentioned above, differences in size, age, origin, different feeding regimens and trophic levels of these species can impact the concentrations of mercury in tuna. Thus, the higher and more variable levels of mer- cury concentrations in the cans of light tuna analyzed in our study could be explained, in part, by the different composition of light tuna in Spain.

With respect to white tuna (Thunnus alalunga), our median of $0.338 \mathrm{mg} / \mathrm{kg}$ was identical to that of the FDA in $2010(0.338 \mathrm{mg} / \mathrm{kg}$ with a mean of $0.353 \mathrm{mg} / \mathrm{kg})$ and the $0.31 \mathrm{mg} / \mathrm{kg}$ found in the Yess study [16,22]. However, it is slightly higher than the mean of $0.21 \mathrm{mg} / \mathrm{kg} \mathrm{ob}-$ served in white tuna in the US Pacific Coast [20]. On the other hand, other authors have observed higher mean levels, such as 0.407 [12] or $0.619 \mathrm{mg} / \mathrm{kg}$ in chunk white tuna [18].

However, most studies have not distinguished between different types of tuna; hence comparisons are difficult. These studies reported very different overall mean mercury: 0.0117 in Iran in the Persia Gulf [23], $0.60 \mathrm{mg} / \mathrm{kg}$ in India [24], $0.21 \mathrm{mg} / \mathrm{kg}$ in Jordan [25] and $0.41 \mathrm{mg} / \mathrm{kg}$ in Italy [26]. The authors of a study carried out in Slovenia found a different mean (with a range from 0.118 to $0.243 \mathrm{mg} / \mathrm{kg}$ ) depending on the origin of the tuna; however they did not specific the type of tuna [27].

Regarding other types of canned tuna, in the present study, we found statistically significant differences between white tuna, light tuna and mackerel, but not between white tuna and light tuna. The median $(0.042 \mathrm{mg} / \mathrm{kg})$ of Pacific (chub) mackerel (Scomber japonicus) analyzed in our study was much lower than that of the other cans of tuna we analyzed and similar to the FDA's finding of 0.08 [16]. The study performed in Slovenia found levels of mercury in mackerel ranging from 0.029 y $0.063 \mathrm{mg} / \mathrm{kg}$, depending on the origin [27]. In addition, some authors have reported that, apart from having low levels of mercury, such as $0.055 \mathrm{mg} / \mathrm{kg}$, canned mackerel contains higher amounts of eicosapentaenoic acid (EPA) and docosahexaenoic acid (DHA), the predominant polyunsaturated fatty acids in canned fish, than other tuna products [17].

With respect to limits set for mercury concentrations in fish, in our study, the limit of $0.500 \mathrm{mg} / \mathrm{kg}$ of mercury was exceeded by $22.2 \%$ of the total of canned tuna. One can of light tuna was over $(1.176 \mathrm{mg} / \mathrm{kg})$ the limit set in Spain $(1 \mathrm{mg} / \mathrm{kg})$, exceeding the limit of $0.500 \mathrm{mg} / \mathrm{kg}$ of mercury by $33.3 \%$. Other studies have also found concentrations that surpass the legal limits, such as a study performed in Italy, where $8.9 \%$ of the total surpassed the limit of $1 \mathrm{mg} / \mathrm{kg}$ [26]. Other researchers found $55 \%$ of samples above the EPA safety level $(0.5 \mathrm{mg} / \mathrm{kg})$ and $5 \%$ that exceeded the FDA limit $(1 \mathrm{mg} / \mathrm{kg})$ [18]; in other studies, $25 \%$ of white tuna samples exceeded $0.5 \mathrm{mg} / \mathrm{kg}$ [12].

As a separate point, we found no differences among brands, prices, expiration dates or packaging medium. This is consistent with the findings of other authors, although Yess reported a significantly higher concentration 
in water than in oil, probably because in this study the sample was mixed in the oil medium, rather than drained off, which would result in a dilution of total $\mathrm{Hg}$ [22].

Our overall median $(0.298 \mathrm{mg} / \mathrm{kg})$ of mercury concentrations in canned tuna is higher than those reported by other authors, such as the mean of $0.17 \mathrm{mg} / \mathrm{kg}$ found in the FDA's 1991 study [22]; however in Yess's study, as clarified by Burger \& Gochfeld, light tuna made up 2/3 of the sample, resulting in an unweighted mean of 0.17 $\mathrm{mg} / \mathrm{kg}$. In addition, the authors arbitrarily set all nondetectable values to 0 ; hence their results were biased downward. Based on the Yess paper, the FDA posts 0.17 on its web site as the value for canned tuna and uses it in its exposure and risk assessments; no mention was made of the white versus light discrepancy, even though it was recognized by Yess [12]. In this regard, some authors also believe that the EPA and FDA should complete their ongoing effort to revise their joint advisory on seafood consumption and mercury exposure and it should not list canned light tuna as a "low mercury" choice, since it is nothing of the sort [19]. Furthermore, according to Shim et $a l$., in order to protect at risk populations, the action level for commercial fish should be reduced to 0.185 , or products exceeding this level should be labeled with an appropriate warning. They also add that due to young children's susceptibility to the toxic effects of mercury, labeling of fish products that are low in mercury, such as mackerel, should be encouraged using a "kidsafe" emblem [17].

The main limitation of the study described herein lies in the fact that it is a descriptive study with a small sample size, which may influence the precision of the estimates in each of the analyzed groups. In spite of the small sample size, and taking into account that, to our knowledge, no other Spanish paper on canned tuna has been published, we consider our study to be relevant as demonstrates levels of mercury in canned tuna in Spain for the first time. Our results indicate that before issuing recommendations on canned tuna consumption, particularly to vulnerable populations, further studies should be carried out in order to obtain a broader range of information regarding mercury concentrations.

Another matter for possible future research, particularly in light of the variable results we obtained and the very high mercury concentrations found in some cans of light tuna, would be the damage to brain development caused by short-term exposure "spikes" as opposed to chronic low dose exposure.

Until such further studies can be carried out and due to the lack of labeling information on Spanish canned tuna, not only regarding the mercury concentration but also with respect to the type, origin, age and size of tuna, it is safer to recommend that vulnerable population, such as pregnant women and small children, consume canned mackerel, which has high levels of omega 3 fatty acids and low mercury concentrations.

\section{REFERENCES}

[1] T. W. Clarkson and L. Magos, "The Toxicology of Mercury and Its Chemical Compounds," Critical Reviews in Toxicology, Vol. 36, No. 8, 2006, pp. 609-662. doi:10.1080/10408440600845619

[2] World Health Organization (WHO), "Exposure to Mercury: A Major Public Health Concern,” 2007. http://www.who.int/phe/news/Mercury-flyer.pdf

[3] H. A. Roman, T. L. Walsh, B. A. Coull, E. Dewailly, E. Guallar, D. Hattis, K. Mariën, J. Schwartz, A. H. Stern, K. Virtanen and G. Rice, "Evaluation of the Cardiovascular Effects of Methylmercury Exposures: Current Evidence Supports Development of a Dose-Response Function for Regulatory Benefits Analysis," Environmental Health Perspectives, Vol. 119, No. 5, 2011, pp. 607-614. doi:10.1289/ehp.1003012

[4] European Food Safety Authority, "Mercury in FoodEFSA Updates Advice on Risks for Public Health,” 2012. http://www.efsa.europa.eu/en/press/news/121220.htm

[5] EPA, United States Environmental Protection Agency, "Laws and Regulations," 2001.

http://www.epa.gov/mercury/regs.htm

[6] US Food and Drug Administration, 2011. http://www.fda.gov/Food/GuidanceRegulation/GuidanceDo cumentsRegulatoryInformation/Seafood/ucm2018426.htm

[7] COMMISSION REGULATION (EC) No 1881/2006 of 19 December 2006, "Setting Maximum Levels for Certain Contaminants in Foodstuffs," 2006. http://eur-lex.europa.eu/LexUriServ/LexUriServ.do?uri= CONSLEG:2006R1881:20100701:EN:PDF

[8] E. M. Trasobares Iglesias, "Plomo y Mercurio en Sangre en una Población Laboral Hospitalaria y su Relación con Factores de Exposición," Ph.D. Dissertation, Universidad Complutense, Madrid, 2009

[9] Gobierno de España, Ministerio de Agricultura, Alimentación y Medio Ambiente, "La Alimentación Mes a Mes. Diciembre," 2012.

http://www.magrama.gob.es/es/alimentacion/temas/consu mo-y-comercializacion-y-distribucion-alimentaria/Inform e_MES_A_MES_Diciembre_2012_tcm7-266150.pdf

[10] NOAA-FishWatch, "Top 10 U.S. Consumed Seafoods," 2012.

http://www.aboutseafood.com/about/about-seafood/top-10consumed-seafoods

[11] Atuna, "Tuna Species Guide," 2013. http://www.atuna.com/

[12] J. Burger and M. Gochfeld, "Mercury in Canned Tuna: White versus Light and Temporal Variation," Environmental Research, Vol. 96, No. 3, 2004, pp. 239-249. doi:10.1016/j.envres.2003.12.001

[13] EPA, United States Environmental Protection Agency \& Food and Drug Administration, "What You Need to Know about Mercury in Fish and Shellfish," 2004. http://water.epa.gov/scitech/swguidance/fishshellfish/outr 
each/upload/2004 0524 fish MethylmercuryBrochure.p df

[14] Ministerio de Sanidad, Servicios Sociales e Igualdad. Agencia Española de Seguridad Alimentaria y Nutrición, "Preguntas Frecuentes," 2013. http://www.aesan.msc.es/SIAC-WEB/pregunta.do;jsessio nid=9KTTR0mTbXWfYlpntHbTQGzjjTMyPhpmHngQ3 6TMsS1LKT0TL8v7!2011555898? reqCode=retrieve\&be an.id $=1201$

[15] Real Decreto $1385 / 2009$, de 28 de Agosto, por el que se Modifica el Real Decreto 1521/1984, de 1 de Agosto, "Por el que se Aprueba la Reglamentación Técnico-Sanitaria de los Establecimientos y Productos de la pesca y Acuicultura con Destino al Consumo Humano," 2009.

[16] US Food and Drug Administration, "Mercury Levels in Commercial Fish and Shellfish (1990-2010)," 2013. http://www.fda.gov/Food/FoodborneIllnessContaminants/ Metals/ucm115644.htm

[17] S. M. Shim, L. E. Dorworth, J. A. Lasrado and C. R. Santerre, "Mercury and Fatty Acids in Canned Tuna, Salmon, and Mackerel," Journal of Food Science, Vol. 69, No. 9, 2004, pp. C681-C684. doi:10.1111/j.1365-2621.2004.tb09915.x

[18] S. L. Gerstenburger, A. Martinson and J. L. Kramer, "An Evaluation of Mercury Concentrations in Three Brands of Canned Tuna," Environmental Chemistry, Vol. 29, No. 2, 2010, pp. 237-242. doi:10.1002/etc.32

[19] E. Groth, Mercury Police Project, "Tuna Surprise: Mercury in School Lunches," 2012. http://mercurypolicy.org/wp-content/uploads/2012/09/es9 15 final.pdf

[20] J. Ruelas-Inzunza, C. Patiño-Mejía, M. Soto-Jiménez, G. Barba-Quintero and M. Spanopoulos-Hernández, "Total Mercury in Canned Yellowfin Tuna Thunnus albacares Marketed in Northwest Mexico," Food and Chemical Toxicology, Vol. 49, No. 12, 2011, pp. 3070-3073. doi:10.1016/j.fct.2011.07.030

[21] S. M. Silbernagel, D. O. Carpenter, S. G. Gilbert, M. Gochfeld, E. Groth III, J. M. Hightower and F. M. Schiavone, "Recognizing and Preventing Overexposure to Methylmercury from Fish and Seafood Consumption: Information for Physicians," Journal of Toxicology, Vol. 2011, 2011, Article ID: 983072. doi:10.1155/2011/983072

[22] N. J. Yess, "U.S. Food and Drug Administration Survey of Methylmercury in Canned Tuna," Journal of $A O A C$ International, Vol. 76, No. 1, 1993, pp. 36-38.

[23] F. E. Khansari, M. Ghazi-Khansari and M. Abdollahi, "Heavy Metals Content of Canned Tuna Fish," Food Chemistry, Vol. 93, No. 2, 2005, pp. 293-296. doi:10.1016/i.foodchem.2004.09.025

[24] M. Mahalakshmi, S. Balakrishnan, K. Indira and M. Srinivasan, "Characteristic Levels of Heavy Metals in Canned Tuna Fish," Journal of Toxicology and Environmental Health Sciences, Vol. 4, No. 2, 2012, pp. 43-45.

[25] F. A. Ababneh and I. F. Al-Momani, "Levels of Mercury, Cadmium, Lead and other Selected Elements in Canned Tuna Fish Commercialised in Jordan," International Journal of Environmental Analytical Chemistry, Vol. 93, No. 7, 2013, pp. 755-766. doi:10.1080/03067319.2012.672981

[26] M. M. Storelli, G. Barone, G. Cuttone, D. Giungato and R. Garofalo, "Occurrence of Toxic Metals ( $\mathrm{Hg}, \mathrm{Cd}$ and $\mathrm{Pb}$ ) in Fresh and Canned Tuna: Public Health Implications," Food and Chemical Toxicology, Vol. 48, No. 11, 2010, pp. 3167-3170. doi:10.1016/j.fct.2010.08.013

[27] A. Miklavcic, V. Stibilj, E. Heath, T. Polak, J. S. Tratnik, J. Klavz, D. Mazej and M. Horvat, "Mercury, Selenium, PCBs and Fatty Acids in Fresh and Canned Fish Available on the Slovenian Market," Food Chemistry, Vol. 124, No. 3, 2011, pp. 711-720. doi:10.1016/j.foodchem.2010.06.040 